\title{
DFT Study on 4(5)-Imidazole-carbaldehyde-N(5)- phenylthiosemicarbazone (ImTPh): NMR Shielding Tensors, Thermodynamic Parameters, NBO Analysis, Molecular Electrostatic Potential (MEP), HOMO and LUMO Studies
}

\author{
MASOOME SHEIKHI, MOHAMMAD MAHMOODI HASHEMI* and MAJID MONAJJEMI \\ Department of Chemistry, College of Basic Sciences, Tehran Science \\ and Research Branch, Islamic Azad University, Tehran, Iran. \\ ${ }^{*}$ Corresponding author E-mail: mmhashemi49@gmail.com
}

http://dx.doi.org/10.13005/ojc/300146

(Received: January 03, 2014; Accepted: February 08, 2014)

\begin{abstract}
The density functional theory (DFT) calculations at the level of B3LYP/6-31G was carried out on the structure 4(5)-Imidazole-carbaldehyde-N(5)-phenylthiosemicarbazone (ImTPh) in gas phase using Gaussian 03. Dipole moment (Debye), energy of structure formation (HF; $\mathrm{kcal} / \mathrm{mol}$ ) and point group, NMR parameters such as isotropic shielding $\left(\sigma_{\text {iso }}\right)$ and anisotropic shielding $\left(\sigma_{\text {aniso }}\right), \sigma_{11}, \sigma_{22}$ and $\sigma_{33}$ obtained. Also thermodynamic properties and natural bond orbitals (NBO) were calculated. Besides, the frontier molecular orbital (FMO) analysis and the molecular electrostatic potential (MEP) of the compound were investigated by theoretical calculations.
\end{abstract}

Key words: DFT; ImTPh; NMR parameter; Thermodynamic parameter; NBO; FMO; MEP.

\section{INTRODUCTION}

Imidazole is an organic compound with the formula $\mathrm{C}_{3} \mathrm{H}_{4} \mathrm{~N}_{2}$. This aromatic heterocyclic is classified as an alkaloid. Imidazole refers to the parent compound whereas imidazoles are a class of heterocycles with similar ring structure but varying substituents. The imidazole nucleus is well known to play an important role in living organisms since it is incorporated into the histidine molecule and many other important biological systems. Imidazole derivatives show various pharmacological activities such as antifungal and anti-bacterial activity ${ }^{1}$, anti inflammatory activity and analgesic activity ${ }^{2}$, antitubercular activity ${ }^{3}$, anti depressant activity, anti cancer activity ${ }^{4}$, antiviral activity ${ }^{5}$ and antileishmanial activity. Due to their antifungal properties imidazolederived compounds have been used in agriculture as effective ingredients for controlling plants pests. Imidazole derivatives are employed in the control of spoilage microorganisms or organisms potentially harmful to man, in the protection of wood against fungi and also in food storage ${ }^{6}$. Thiosemicarbazones ${ }^{7,8}$ and hydrazones ${ }^{9}$ are reported as compounds which 
present significant antifungal activity. The imidazolederived thiosemicarbazones were prepared by reacting of 4(5)-imidazole-carboxaldehyde, 4- $(1 \mathrm{H}$ imidazole-1-yl)-benzaldehyde or 4-(1H-imidazole-1yl)- acetophenone with the suitable thiosemicarbazide using methanol as solvent ${ }^{10}$. In the present work we carried out theoretical calculations on one of the imidazole-derived thiosemicarbazones, that is named 4(5)-Imidazole-carbaldehyde- $\mathrm{N}(5)$ phenylthiosemicarbazone (ImTPh).

\section{Theoretical calculations}

We have carried out quantum theoretical calculations of ImTPh using DFT (B3LYP) method with $6-31 \mathrm{G}$ basis set by the Gaussian 03 program ${ }^{11}$. We calculated ${ }^{1} \mathrm{H}$ and ${ }^{13} \mathrm{C}$ NMR chemical shifts of ImTPh using B3LYP/6-31G level within GIAO approach. Moreover was studied thermodynamic parameters of ImTPh using methods listed, and obtained the energy $(\Delta \mathrm{E})$, enthalpies $(\Delta \mathrm{H})$, Gibbs free energy $(\Delta G)$, entropies $(S)$ and constant volume molar heat capacity $\left(\mathrm{C}_{\mathrm{v}}\right)$ of derivatives ${ }^{12}$. Some electronic properties such as energy of the highest occupied molecular orbital $\left(\mathrm{E}_{\mathrm{Hомо}}\right)$, energy of the lowest unoccupied molecular orbital $\left(E_{\text {LUMO }}\right)$, energy gap $(\mathrm{Eg} ; \Delta$ ) between LUMO and HOMO, atomic charges, dipole moment $(\mu)$ and Point group were determined. The optimized molecular structures,
HOMO and LUMO surfaces were visualized using GaussView 03 program ${ }^{13}$.

We also studied electronic structures of ImTPh using Natural Bond Orbital (NBO) analysis using level of B3LYP/6-31G. The main listing of NBOs, displaying the form and occupancy of the complete set of NBOs that span the input AO space and for each orbital gives the type of orbital and the occupancy ${ }^{14}$.

\section{DISCUSSION}

The optimized molecular structure of ImTPh was calculated using Gaussian 03 software. The optimized geometrical parameters, such as Dipole moment (Debye), energy of structure formation (HF; $\mathrm{kcal} / \mathrm{mol}$ ) and point group, obtained using B3LYP method and 6-31G as the basis set that are listed in Table 1. As shown in Table 1, ImTPh has $C_{1}$ point

Table 1: Dipole moment, HF and Point group of ImTPh obtained using B3LYP/6-31G level

\begin{tabular}{lcc}
\hline HF (kcal/mol) & $\begin{array}{c}\text { Dipole moment } \\
\text { (Debye) }\end{array}$ & $\begin{array}{c}\text { Point } \\
\text { group }\end{array}$ \\
\hline-688676.535 & 5.4185 & $\mathrm{C}_{1}$ \\
\hline
\end{tabular}

Table 2. NMR shielding tensors values of ImTPh obtained using B3LYP/6-31G level

\begin{tabular}{lccccc}
\hline & $\sigma_{\text {iso }}$ & $\sigma_{\text {aniso }}$ & $\sigma_{11}$ & $\sigma_{22}$ & $\sigma_{33}$ \\
\hline $\mathrm{C}_{1}$ & 68.109 & 105.736 & 7.598 & 58.129 & 138.600 \\
$\mathrm{C}_{2}$ & 63.816 & 114.798 & -4.365 & 55.464 & 140.347 \\
$\mathrm{C}_{4}$ & 61.335 & 97.839 & -8.789 & 66.234 & 126.561 \\
$\mathrm{C}_{6}$ & 68.474 & 100.343 & -12.944 & 82.998 & 135.369 \\
$\mathrm{C}_{9}$ & 15.892 & 121.787 & -128.044 & 78.637 & 97.084 \\
$\mathrm{~N}_{3}$ & -40.283 & 409.594 & -268.882 & -84.746 & 232.779 \\
$\mathrm{~N}_{5}$ & 102.382 & 121.185 & 8.110 & 115.864 & 183.172 \\
$\mathrm{~N}_{7}$ & -71.636 & 380.997 & -353.853 & -43.418 & 182.361 \\
$\mathrm{~N}_{8}$ & 79.316 & 93.185 & 6.673 & 89.836 & 141.440 \\
$\mathrm{~N}_{11}$ & 123.777 & 105.585 & 40.554 & 136.610 & 194.167 \\
$\mathrm{H}_{19}$ & 25.353 & 3.797 & 22.976 & 25.199 & 27.884 \\
$\mathrm{H}_{20}$ & 23.747 & 9.631 & 17.025 & 24.049 & 30.168 \\
$\mathrm{H}_{21}$ & 25.080 & 5.337 & 22.776 & 23.826 & 28.638 \\
$\mathrm{H}_{22}$ & 25.696 & 3.834 & 22.484 & 26.352 & 28.252 \\
$\mathrm{H}_{23}$ & 26.829 & 8.131 & 19.613 & 28.624 & 32.250 \\
\hline
\end{tabular}




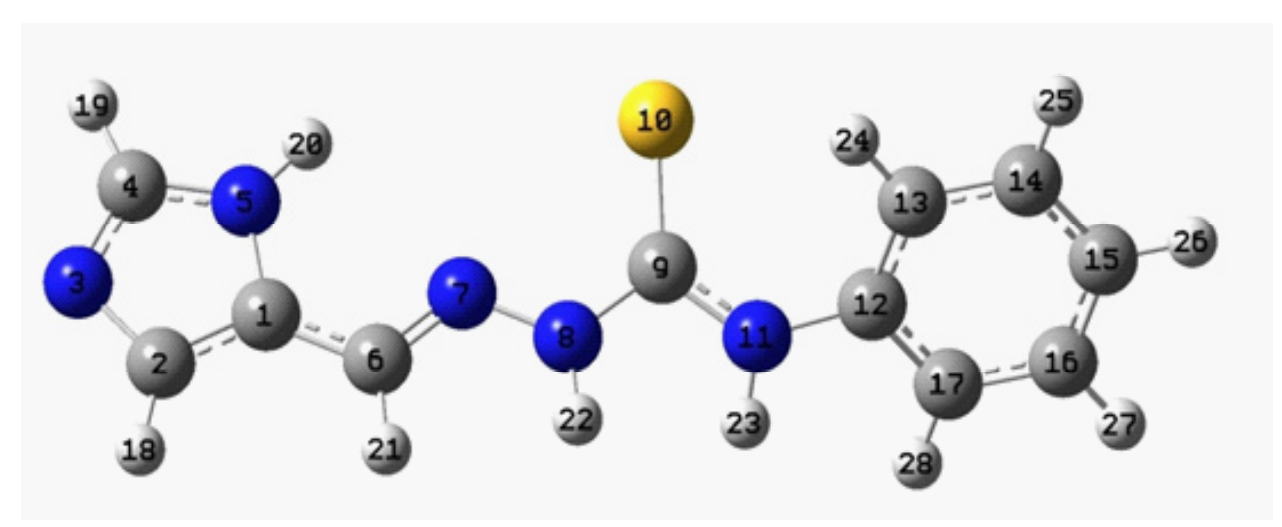

Fig. 1: Structure of ImTPh

group symmetry and Dipole moment $(\mu)$ value is 5.4185. Also the energy of structure formation (HF) of ImTPh is negative.

\section{NMR Parameters}

In this section we report and analyze NMR shielding tensors of ${ }^{1} \mathrm{H},{ }^{13} \mathrm{C},{ }^{15} \mathrm{~N}-\mathrm{NMR}$ such as isotropic shielding $\left(\sigma_{\text {iso }}\right)$ and anisotropic shielding $\left(\sigma_{\text {aniso }}\right), \sigma_{11}, \sigma_{22}, \sigma_{33}$ of ImTPh, which obtain using level of B3LYP/6-31G in gas phase. The chemical shielding anisotropy (CSA) tensors provide important information about electronic environment of the nuclei, which depends on the molecular geometry. The results of our studies are listed Table 2 . According to Table 2 , isotropic shielding value $\left(\sigma_{\text {iso }}\right)$ and anisotropic shielding value $\left(\sigma_{\text {aniso }}\right)$ for $C_{1}, C_{2}, C_{4}$, $\mathrm{C}_{6}, \mathrm{C}_{9}$ atoms are a positive values. Of carbon atoms mentioned, $\mathrm{C}_{9}$ has the lowest isotropic shielding and the highest anisotropic shielding value. The isotropic shielding value of $\mathrm{N}_{3}$ and $\mathrm{N}_{7}(-\mathrm{C}=\mathrm{N})$ is negative and

Table 3. The calculated thermodynamic parameters of ImTPh using B3LYP/6-31G level

\begin{tabular}{ccccc}
\hline$\Delta \mathrm{E}(\mathrm{Kcal} / \mathrm{mol})$ & $\Delta \mathrm{G}(\mathrm{Kcal} / \mathrm{mol})$ & $\Delta \mathrm{H}(\mathrm{Kcal} / \mathrm{mol})$ & $\mathrm{S}(\mathrm{cal} / \mathrm{molK})$ & $\mathbf{C}_{\mathrm{v}}(\mathrm{cal} / \mathrm{molK})$ \\
\hline-688530.795 & -688568.278 & -688530.202 & 127.707 & 55.106 \\
\hline
\end{tabular}

anisotropic shielding for these atoms is the highest value. The isotropic and anisotropic shielding values of hydrogen atoms are positive. The $\mathrm{H}_{20}$ has the lowest isotropic shielding and the highest anisotropic shielding value. Therefore $\mathrm{H}_{20}$ is the most acidic hydrogen.

\section{Frequency calculations}

Thermodynamic parameters such as the relative energy $(\Delta \mathrm{E})$, standard enthalpies $(\Delta \mathrm{H})$, entropies $(\Delta S)$, Gibbs free energy $(\Delta G)$ and constant volume molar heat capacity $\left(C_{v}\right)$ values of ImTPh were obtained using B3LYP/6-31G level. The values are listed in Table 3 showed that relative energy, Gibbs free energy and standard enthalpies of ImTPh are negative that we found this structure is stable.

\section{NBO analysis}

In accordance with the simple bond orbital picture, each bonding NBO is introduced as an orbital formed from two directed valence hybrids (NHOs) hA, hB on atoms $A$ and $B$, with corresponding polarization coefficients $\mathrm{cA}$, cb. Table 3 show share of orbitals contribute in the bonds (BD for 2-center bond). As shown in Table 4, in the $\mathrm{N}_{5}-\mathrm{H}_{20}$ bond, $\mathrm{BD}=0.8603 \mathrm{sp}^{2.19}+0.5097 \mathrm{~s}$ reported. Thus polarization coefficients of the $\mathrm{N}_{5}-\mathrm{H}_{20}$ bond $\mathrm{N}_{5}=0.8603$ and $\mathrm{H}_{20}=0.5097$ reported, that sizes of these coefficients show hybrid of $\mathrm{N}_{5}$ is more important in the formation of the $\mathrm{N}_{5}-\mathrm{H}_{20}$ bond. Also in $\mathrm{N}_{8}-\mathrm{H}_{22}$ and $\mathrm{N}_{11}-\mathrm{H}_{23}$ bonds, polarization coefficient values of $\mathrm{N}_{8}$ and $\mathrm{N}_{11}$ is larger than $\mathrm{H}_{22}$ and $\mathrm{H}_{23}$. The of polarization coefficient values of $\mathrm{H}_{20}, \mathrm{H}_{22}$ and $\mathrm{H}_{23}$ is $0.5097,0.5366$ and 0.5344 , respectively. This show 
Table 4: Calculated natural bond orbitals (NBO) and the polarization coefficient for each hybrid in N-H bonds of ImTPh

\begin{tabular}{llllll}
\hline & BD* & & \multicolumn{3}{l}{ BD } \\
B & A & A-B & B & A & A-B \\
\hline $\mathrm{s}(-0.8603)$ & $\mathrm{sp}^{2.19}(0.5097)$ & $\mathrm{N}_{5}-\mathrm{H}_{20}$ & $\mathrm{~s}(0.5097)$ & $\mathrm{sp}^{2.19}(0.8603)$ & $\mathrm{N}_{5}-\mathrm{H}_{20}$ \\
$\mathrm{~s}(-0.8438)$ & $\mathrm{sp}^{2.59}(0.5366)$ & $\mathrm{N}_{8}-\mathrm{H}_{22}$ & $\mathrm{~s}(0.5366)$ & $\mathrm{sp}^{2.37}(0.8438)$ & $\mathrm{N}_{8}-\mathrm{H}_{22}$ \\
$\mathrm{~s}(-0.8452)$ & $\mathrm{sp}^{2.59}(0.5344)$ & $\mathrm{N}_{11}-\mathrm{H}_{23}$ & $\mathrm{~s}(0.5344)$ & $\mathrm{sp}^{2.90}(0.8452)$ & $\mathrm{N}_{11}-\mathrm{H}_{23}$ \\
\hline
\end{tabular}

${ }^{*}$ Antibonding

that share of contribute $\mathrm{H}_{20}$ in bond $\mathrm{N}_{5}-\mathrm{H}_{20}$ is lower than share of $\mathrm{H}_{22}$ and $\mathrm{H}_{23}$ in $\mathrm{N}_{8}-\mathrm{H}_{22}$ and $\mathrm{N}_{11}-\mathrm{H}_{23}$ bonds, respectively.

\section{Frontier Molecular Orbital (FMO) Analysis}

The $\mathrm{E}_{\text {номо }}, \mathrm{E}_{\text {LUMO }}$ and HOMO-LUMO energy gap $(\mathrm{Eg} ; \Delta)$ of ImTPh was calculated using the B3LYP method and 6-31G basis set. The properties of molecular orbitals such as energy and frontier electron density are important and are used to determine the reactive position.
According to Fig. 2, the HOMO energy and the LUMO energy ( $\left.E_{\text {LUMO }}\right)$ of ImTPh is $-5.61 \mathrm{eV}$ and $-1.74 \mathrm{eV}$, respectively. Also Fig.2 and spectrum DOS (Fig. 3) show that energy gap of ImTPh is $3.87 \mathrm{eV}$. As shown in Fig. 2, the HOMO is focused mainly around and sulfur atom and imidazole ring.

\section{Molecular Electrostatic Potential}

Molecular electrostatic potential (MEP) is relevant to the electronic density and it to specify the locations sites of electrophilic and nucleophilic ${ }^{15}$.

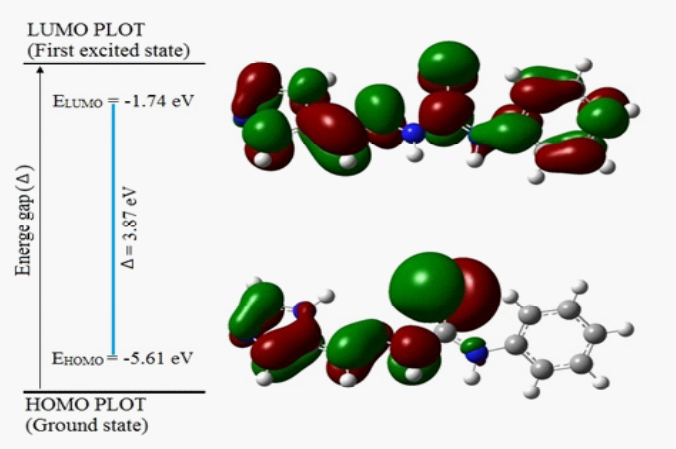

Fig. 2: Frontier molecular orbitals of ImTPh. ( $\Delta$ : Energy gap between LUMO and HOMO)

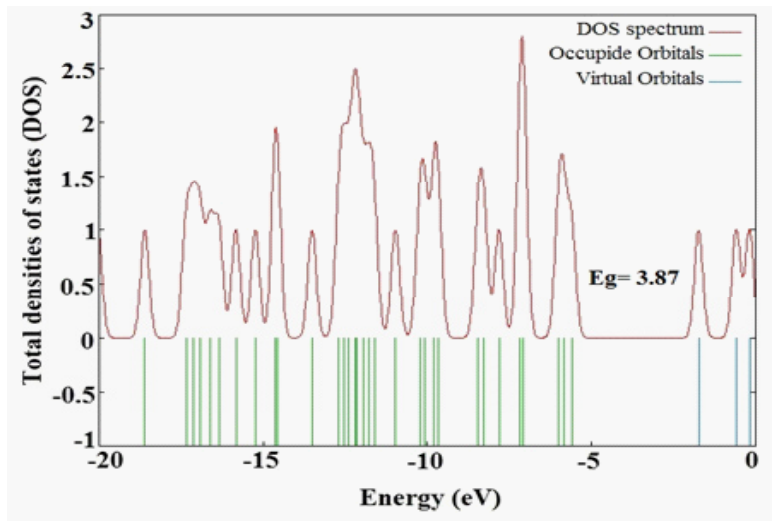

Fig. 3: Total densities of states (DOSs) for ImTPh 


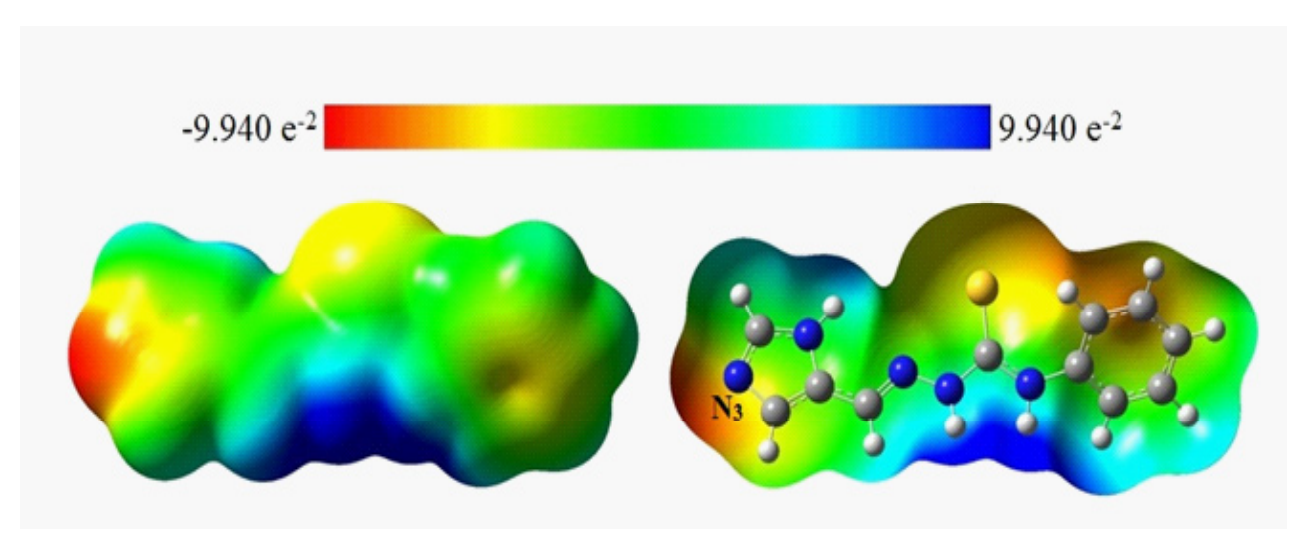

Fig. 4: Molecular electrostatic potential map of ImTPh

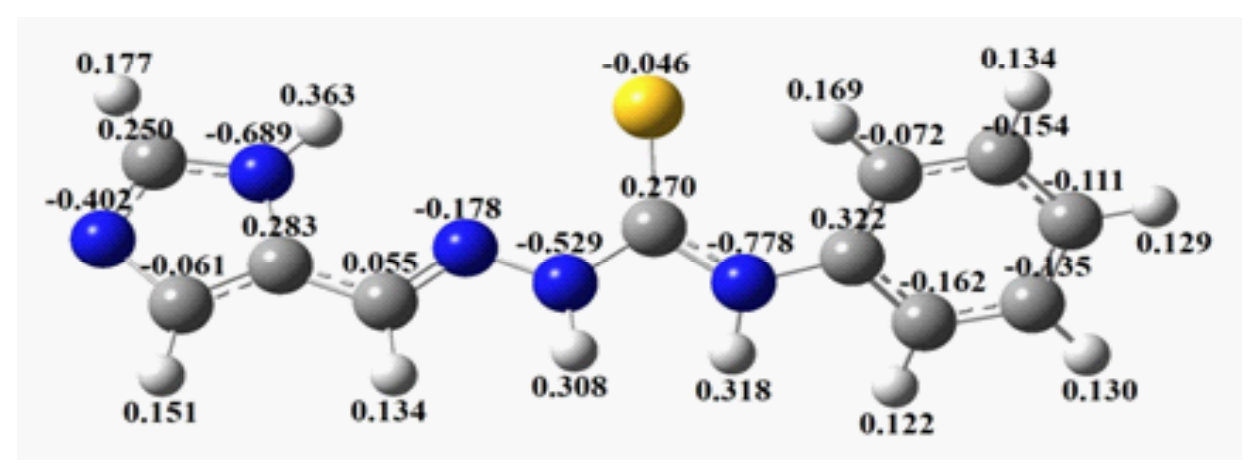

Fig. 5: Atomic charge of atoms of ImTPh

MEP methodology studies the electronic distribution in the molecule ${ }^{16}$. The optimized geometry of ImTPh to indicate sites of electrophilic and nucleophilic, MEP was calculated using B3LYP method and 6-31G basis set.

As shown in Fig. 4, nitrogen atom of imidazole ring $\left(\mathrm{N}_{3}\right)$ has maximum electronic density (red color). Therefore $\mathrm{N}_{3}$ is main negative center. Also lowest electron density is observed for hydrogen atoms bound to nitrogen (blue color).

The atomic charge of atoms of ImTPh is shown in Fig. 5. As can be seen in Fig. $5, \mathrm{H}_{20}$ (Hydrogen attached to the nitrogen in the imidazole ring) has the most positive charge.

\section{CONCLUSION}

In the present work, we have performed theoretical analyses of 4(5)-Imidazole-carbaldehyde$\mathrm{N}(5)$-phenylthiosemicarbazone (ImTPh). The following conclusions are obtained from the current study:

1. The point group symmetry, Dipole moment $(\mu)$ and energy of structure formation (HF) of ImTPh is C1, 5.4185 and -688676.535, respectively.

2. As regards hydrogen bonded to nitrogen of imidazole ring $\left(\mathrm{H}_{20}\right)$ has the lowest valu of $\sigma_{\text {iso }}$ and $\sigma_{\text {aniso }}$, therefore $\mathrm{H}_{20}$ the most acidic hydrogen of ImTPh.

3. According to the thermodynamic parameters, we find that amount of Gibbs free energy $(\Delta \mathrm{G})$, standard enthalpies $(\Delta \mathrm{H})$ and internal thermal energy $(\Delta \mathrm{E})$ of ImTPh is negative value, therefore ImTPh is stable structure.

4. Among hydrogens bonded to nitrogen, $\mathrm{H}_{20}$ in bond $\mathrm{N}_{5}-\mathrm{H}_{20}$ has the lowest polarization coefficient. This suggests that $\mathrm{H}_{20}$ in imidazole ring is the most acidic hydrogen of ImTPh.

5. According to FMO analysis, the HOMO is focused mainly around and sulfur atom and imidazole ring. 
6. As shown MEPs, the maximum electron density is located on the nitrogen atom $\left(\mathrm{N}_{3}\right)$ imidazole ring.

7. Finally, Our results confirm the biological properties of compounds containing the imidazole ring among 4(5)-Imidazolecarbaldehyde-N(5)-phenylthiosemi carbazone (ImTPh).

\section{REFERENCES}

1. Shingalapur R. V., Hosamani K. M., Keri R. S., European Journal of Medicinal Chemistry, 44: 4244-4248 (2009).

2. Puratchikodya A., Doble M., Bioorganic \& Medicinal Chemistry. 15: 1083-1090 (2007).

3. Pandey J., Tivari V. K., Verma S. S., Chaturvedi V., Bhatnagar S., Sinha S., Gaikwad A. N., Tripathi R. P., European Journal of Medicinal Chemistry, 44: 3350-3355 (2009).

4. Ramla M. M., Mohamed A., Abdel-Momen M., Kharmry E., Hoda I., Diwani E., Bioorg. Med. Chem., 14: 7324-7332 (2006).

5. Tonelli M., Simone M., Tasso B., Novelli F., Boido V., Bioorganic \& Medicinal Chemistry, 18: 2937-2953 (2010).

6. Melander C., Cavanagh J., Ritchie D. F., Rogers S. A., Robert W., Inhibition and dispersion of biofilms in plants with imidazole-triazole derivatives, WIPO Patent 2010077603, 8 July (2010).

7. Pervez H., Iqbal M. S., Tahir M. Y., Nasim F., Choudhary M. I., Khan K. M., J. Enzym. Inhib. Med. Chem., 23: 848-854 (2008).
8. Beraldo H., Gambino D., Min. Rev. Med. Chem., 4: 159-165 (2004)

9. Rollas S., Küçükgüzel ^. G., Molecules, 12: 1910-1939 (2007).

10. Débora C. R., Angel A. Recio., Jeferson G. D., Nayane F. S., Camila F. V., Isolda C. M., Jacqueline A. T., Heloisa B., Molecules, 18: 12645-12662 (2013)

11. M.J. Frisch et al., Gaussian 03, revision B03, Gaussian Inc., Pittsburgh, PA, 2003.

12. Monajjemi M., Afsharnezhad S., Jaafari M. R., Abdolahi T., Nikosade A., Monajemi H., Russ. J. Phys. Chem. A, 81: 1956-1963 (2007).

13. Frisch A., Nielson A. B., Holder A. J., GAUSSVIEW User Manual, Gaussian Inc., Pittsburgh, PA (2000).

14. Seyed Katouli S. A., Sheikhi M., Seikh D., Tayyari S. F., Orient. J. Chem., 29: 1121-1128 (2013).

15. Luque F. J., Lopez J. M., Orozco M., Theor. Chem. Acc., 103: 343-345 (2000).

16. Ramachandran S., Velraj G., Rom. Journ. Phys., 58: 305-318 (2013). 